\title{
O USO DAS MIDIAS DIGITAIS COMO FERRAMENTA DE DIVULGAÇÃO DA GESTÃO AMBIENTAL EMPRESARIAL: UMA RELAÇÃO ENTRE SUSTENTABILIDADE E LUCRATIVIDADE
}

\author{
Alvaro Costa Jardim Neto, Jéssica Cristina Jordão Sant’ana, Valdecir Cahoni Rodrigues \\ Universidade do Oeste Paulista - UNOESTE, Curso de Administração e Curso Superior de Tecnologia em Gestão de \\ Recursos Humanos, Presidente Prudente - SP. e-mail: alvaro@unoeste.br
}

\begin{abstract}
RESUMO
Atualmente os programas de sustentabilidade das organizações estão diretamente relacionados com o aumento de sua lucratividade. Com consumidores mais exigentes e conscientes as empresas têm utilizado estas mudanças como forma estratégica de divulgação de suas práticas nas mídias sociais como forma de melhorar a sua imagem. O método utilizado para esta pesquisa foi bibliográfica com a utilização dos principais autores que abordam este tema. $O$ objetivo foi demonstrar os benefícios proporcionados pela divulgação das práticas sustentáveis das organizações através do marketing digital. Através da pesquisa concluiu-se que vários são os benefícios tais como melhoria na imagem da empresa, custo zero para a divulgação, alcance mais facilmente de seu público alvo, etc.
\end{abstract}

Palavras-chave: Mídias digitais, Sustentabilidade, Gestão Ambiental.

USE OF DIGITAL MEDIA AS A TOOL OF CORPORATE DISCLOSURE OF ENVIRONMENTAL MANAGEMENT: A RELATIONSHIP BETWEEN SUSTAINABILITY AND PROFITABILITY

\begin{abstract}
Currently sustainability programs of organizations are directly related to the increase of its profitability. With more demanding and aware consumer companies have used these changes as a strategic form of disclosure of their practices in social media as a way to improve its image. The method used for this research was literature with the use of the main authors who address this topic. The objective was to demonstrate the benefits of sustainable practices for the disclosure of organizations through digital marketing. Through research it was found that there are several benefits such as improved image of the company, zero cost to the disclosure, more easily reach your target audience, etc.

Keywords: Digital Media, Sustainability, Environmental Management.
\end{abstract}




\section{INTRODUÇÃO E OBJETIVO}

Não há mais como uma organização manter-se competitiva perante os seus concorrentes sem implantar uma gestão sustentável em seus negócios. Cada dia mais com o fenômeno da globalização o conceito sustentabilidade vem sendo disseminado entre as corporações e a própria sociedade. Para isto estas organizações procuram desenvolver políticas e ferramentas, adequando-se as novas legislações ambientais.

As empresas vêm percebendo que o numero de clientes chamados "ecologicamente corretos" vem aumentando gradativamente. Assim empresas que procuram expandir seus negócios arrebanhando novos clientes não podem deixar de investir em sustentabilidade vinda assim a conquistar novos clientes que se traduz em aumento de lucratividade.

Devido ao grande aumento de consumidores que buscam adquirir somente produtos de empresas que não degradam o meio ambiente, os gestores devem identificar uma maneira satisfatória tanto para a empresa quanto para o consumidor de desenvolver programas de gestão ambiental que, mesmo em longo prazo, forneça um retorno desejável a organização.

Além da questão ambiental, o consumidor hoje está muito atento e demonstra preocupação com o ambiente em que estamos vivendo e irá cada vez mais apoiar empresas que se preocupam com isto, que conscientizam a população sobre o assunto e tenham políticas a favor do meio ambiente (MANANGEMENT, 2007).

Para muitos gestores que estão atentos aos novos consumidores, tal fato tem se tornado uma ferramenta poderosíssima em suas mãos, pois as empresas têm aproveitado estes programas para se promoverem e mostrarem aos seus clientes que estão realmente preocupados com a questão ambiental, e que estão investindo financeiramente para reduzir a sua degradação, criando metas para projetos que trarão resultado para o ambiente e para a sociedade em geral. Ao agir desta maneira as empresas estão fidelizando seus clientes em suas marcas e tornando-se mais competitiva no mercado.

Esta pesquisa tem por objetivo demonstrar através de um levantamento bibliográfico os benefícios proporcionados pela divulgação das práticas sustentáveis das organizações através do marketing digital.

\section{METODOLOGIA}

Este estudo teve caráter bibliográfico, resgatando autores consagrados para a discussão do conceito de desenvolvimento sustentável e sustentabilidade. Os textos de autores como Bazoli (2009), Silva (2005), Savitz (2006), Porter e Linde (1995) 
forneceram embasamentos teóricos e dados bibliográficos que permitiram discussões acerca do tema proposto.

\section{RESULTADOS}

\subsection{Sustentabilidade e Desenvolvimento}

\section{Sustentável}

O conceito de desenvolvimento sustentável provém de um processo histórico que reavalia a relação existente entre sociedade civil e seu meio natural. A empresa retira do meio ambiente por intermédio de matéria prima e transforma em produto para satisfazer seus clientes. A ideia de sustentabilidade está ligada a persistência de certas características necessárias e desejáveis de pessoas, suas comunidades e organizações, e os ecossistemas que as envolvem, dentro de um período de tempo longo ou indefinido (BAZOLI, 2009).

\section{A sustentabilidade e o} desenvolvimento sustentável afloram nesse cenário não como uma questão dicotômica, mas próprio de um processo cuja primeira se relaciona com o fim, ou o objetivo maior, e o segundo com o meio. Esta distinção, contudo, está imersa a uma discussão ideológica que se insere em pensar algo para o futuro ou se preocupar com ações presentes e impactos no futuro (SILVA, 2005). Entende-se que o desenvolvimento sustentável é o que atende as necessidades das gerações presentes sem comprometer a possibilidade das gerações futuras atenderem as suas próprias necessidades.

\subsubsection{Sustentabilidade e o Triple Bottom} Line

Conhecido como Triple Bottom Line (3BL), ou tratado nacionalmente como Tripé da Sustentabilidade, este termo foi originado em estudos de John Elkington e retrata por Savitz (2006) onde sugere que as empresas observem para medir seu sucesso no desenvolvimento não somente os aspectos econômicos, mas também questões ambientais e sociais.

Esta preocupação surge a partir do momento em que, para uma empresa atuar no mercado se faz necessária observar fatores como os danos ambientais que esta pode gerar questões de imagem da empresa, reputação, além dos aspectos sociais, ou seja, o desenvolvimento que esta empresa pode trazer tanto para a sociedade como para seus colaboradores, gerenciamento de talentos, infraestrutura oferecida para seus membros e outros.

Savitz (2006) afirma ainda que o Triple Botton Line capta a essência da sustentabilidade por medir o impacto das atividades da organização no mundo, além de que o impacto positivo deste reflete em um aumento no valor da empresa, incluindo seu valor de rentabilidade, acionistas e seu capital social, humano e ambiental. 
Para melhor apresentar este modelo de desenvolvimento sustentável Barbieri traz as seguintes definições para as dimensões tratadas por Savitz (2006):

Dimensão social -
preocupação com os
impactos sociais das
inovações nas comunidades
humanas dentro e fora da
organização (desemprego;
exclusão social; pobreza;
diversidade organizacional
etc.); dimensão ambiental
- preocupação com os
impactos ambientais pelo
uso de recursos naturais e
pelas emissões de

poluentes; dimensão econômica - preocupação com a eficiência econômica, sem a qual elas não se perpetuariam. Para as empresas essa dimensão significa obtenção de lucro e geração de vantagens competitivas nos mercados onde atuam. (BARBIERI, 2010; grifo do autor)

A tabela 01 apresenta, de forma simplificada os aspectos de Savitz e alguns pressupostos que envolvem cada uma das dimensões do desenvolvimento sustentável.

Tabela 01. O Tripé da Sustentabilidade - The Triple Bottom Line.

\begin{tabular}{|l|l|l|}
\hline \multicolumn{1}{|c|}{ Econômico } & \multicolumn{1}{|c|}{ Ambiental } & \multicolumn{1}{c|}{ Social } \\
\hline Vendas, lucros, ROI & Qualidade do ar & Práticas trabalhistas \\
\hline Impostos pagados & Qualidade da água & Impactos da Comunidade \\
\hline Fluxos monetários & Uso de energia & Direitos humanos \\
\hline $\begin{array}{l}\text { Criação de postos de } \\
\text { trabalho }\end{array}$ & Resíduos produzidos & $\begin{array}{l}\text { Responsabilidade pelo } \\
\text { produto }\end{array}$ \\
\hline
\end{tabular}

Fonte: Savitz (2006, p. 16) (adaptado pelo autor)

O desenvolvimento sustentável sobre o olhar do 3BL não é observado pelas empresas visto que em sua grande maioria a única preocupação é o lucro, assim a sustentabilidade tende a ser vista como um princípio fundamental da administração eficiente, onde o diferencial para estas práticas esta em tornar-se concedido de que o mercado tem por característica o fundo financeiro, muitas vezes abordado como o único mecanismo para o sucesso.

\subsection{Gestão Ambiental}

A gestão ambiental (GA) é o principal instrumento para se obter um desenvolvimento industrial sustentável. O processo de gestão ambiental nas empresas está profundamente vinculado a normas que são elaboradas pelas instituições públicas (prefeituras, governos estaduais e federais) sobre o meio ambiente. Essas normas fixam os limites aceitáveis de emissão de substâncias poluentes, definem em que 
condições serão despejadas os resíduos na natureza, proíbem a utilização de substâncias tóxicas, define a quantidade de água que pode ser utilizada, volume de esgoto que pode ser lançado etc (DIAS, 2011; MAIMON, 1996).

De acordo com Navarro (2006), temse como exemplos de gestão ambiental o uso de técnicas para a recuperação de áreas degradadas, técnicas de reflorestamento, métodos para a exploração sustentável de recursos naturais, e o estudo de riscos e impactos ambientais para a avaliação de novos empreendimentos ou ampliação de atividades produtivas.

Segundo Porter e Linde (1995), a Gestão Ambiental vem se tornando um plus na competitividade além da questão ambiental ser um fator de grande importância para a melhoria da qualidade de vida - o que gerou a necessidade de que as empresas se atentassem a isso - ela também pode trazer muitos benefícios às organizações, podendo assim ser considerada uma vantagem competitiva.

\subsection{Marketing Digital}

O marketing é um segmento muito importante para todas as organizações se destacarem no mercado nacional e global, uma ferramenta extremamente importante em uma organização, o marketing é responsável boa parte por todo 0 desenvolvimento e lucratividade da empresa, na qual se volta não apenas para simplesmente vender algo, mas conquistar e criar no consumidor uma necessidade ou um desejo.

No mundo de hoje com grandes avanços e mudanças significativas as empresas precisam estar antenadas para acompanhar as evoluções ocorridas com tanta frequência, já que no mercado há uma grande competição de empresas, dessa forma as empresas está utilizando do marketing digital para alcançar áreas, conquistar novos clientes e atingir metas visando sempre o lucro, pois hoje as empresas não precisam mais utilizar de grandes espaços para conseguir fazer uma venda, basta somente ter um meio digital ligado à internet para efetuar uma venda e de tal forma uma compra. E com essa revolução muitas empresas com pouco capital podem utilizar as redes como áreas no qual possam fazer suas vendas, alavancar rendas e alcançar patamares mundiais.

O marketing evoluiu e assim passou a ter outro perfil nas empresas, hoje um novo marketing está no mercado conquistando empresas e se fazendo necessário para a sobrevivência da mesma. Diante disso a nova onda de tecnologia trouxe para as organizações uma nova visão de valores e missões diferenciando das aplicadas nos antigos conceitos de marketing, dessa forma 
o marketing 3.0, como é chamada esse novo conceito, dispõe de uma prática fundamentalizada nos princípios de uma sociedade ainda mais atualizada e exigente.

\section{DISCUSSÃO}

\subsection{Marketing digital na gestão ambiental}

Seguindo com a linha de que as pessoas atualmente estão cada vez mais exigentes, e que o mundo globalizado está em favor disso podemos dizer que os dois assuntos se casam quase que uma forma perfeita. O meio digital é uma porta aberta para o mundo possibilitando ligação direta com seu público e até outras regiões, expandindo o negócio e avançando fronteiras, sem custos altos, apenas exigindo criatividade e tecnologia, assim é com redes sociais, ponto de encontro de diversos perfis seja individualista ou corporativista.

Unindo a sustentabilidade a essa era digital, o marketing se enriquece podendo se aproveitar das mídias para propagar o quão a responsabilidade ambiental e social assumida por uma empresa pode ser muito mais acessível do que se espera, o resultado obtido com esse meio leva os conceitos de sustentabilidade mais expandida, e atrai os consumidores que seguem esse tipo de comportamento consciente, sem contar que a empresa sai ainda mais no lucro.

O marketing digital utiliza-se de uma abordagem da internet e outros meios digitais como instrumento para atingir os seus objetivos, e fazer chegar ao alcance de todos a consciência da gestão ambiental, pois propagando nas mídias digitais expressivas as atitudes tomadas pela organização fará que chegue ao conhecimento de todos de uma forma mais rápida e eficaz a preocupação sustentável da empresa.

\subsection{Benefícios das Práticas Sustentáveis}

Porter e Linde (1995) revela que através das implantações da Gestão Ambiental, já efetuadas nas empresas, diversos resultados positivos foram obtidos. Além de ter competência para concorrer, ou até mesmo sair na frente da concorrência, alcançam: a redução de custos; a possibilidade de conquista de mercados internacionais, por adequar-se a normas de exigência comercial; o cumprimento às exigências das legislações ambientais vigentes; e a melhoria da imagem da empresa pela implantação de um modelo de administração responsável. Porém, naturalmente, não se pode afirmar que todos os setores empresariais já se encontram conscientizados da importância da gestão responsável dos recursos naturais.

Segundo Skaf (apud DIAS, 2011, p.185), "as empresas sofrem sérias pressões para modificar seus processos produtivos e produtos, pois em sua grande parte exportam para países desenvolvidos onde as 
exigências ambientais são maiores por parte dos consumidores". Logo, as empresas socialmente responsáveis, preocupadas com a preservação e interessadas em competir no mercado externo, trabalham cada vez mais para se adaptar à produção limpa. Esse movimento provoca um efeito cascata, pois elas passam a exigir cada vez mais o certificado de gestão ambiental de seus fornecedores. Ainda pode-se dizer que os clientes melhor se conscientizam e se preocupam com essa questão ambiental, aumentando ainda mais à pressão para redução dos impactos ambientais causados pelas empresas.

\section{CONCLUSÃO}

Não há mais como gerir uma organização sem levar em consideração o fator sustentabilidade. Programas adotados pelas empresas tidas como socialmente responsáveis tem se tornado uma estratégia de crescimento em suas vendas. Os consumidores vêm tornando-se mais consciente e exigindo mais das empresas. Neste sentido as organizações estão utilizando as mídias sociais como forma de divulgação de seus programas de responsabilidade social.

Muito mais pessoas estão tendo acesso às mídias sociais. Têm utilizado desta ferramenta tanto para buscarem seus direitos quando se sentem injustiçadas como também para divulgar as experiências positivas de suas aquisições.

Por se tratar de uma ferramenta praticamente gratuita muitos são os benefícios das organizações em utilizar as mídias sócias. Entre elas podemos citar os custos que são praticamente zero; a facilidade de se comunicar com o seu público alvo; a abrangência de uma notícia em curto período de tempo, etc.

\section{REFERÊNCIAS}

BARBIERI, J. C. et al. Inovação e sustentabilidade: novos modelos e proposições. RAE, São Paulo, v. 50, n. 2, abr./jun. 2010.

BAZOLI, T. N. Terceiro setor: parcerias com o Estado à Luz do desenvolvimento social sustentável. Londrina: Saúde em Destaque, 2009.

DIAS, R. Gestão ambiental: responsabilidade social e sustentabilidade. São Paulo: Atlas, 2011.

MANANGEMENT. Ecoinovação, v.04, ano 11, n.63, jul./ago. 2007.

MAIMON, D. Passaporte verde: gerência ambiental e competitividade. Rio de Janeiro: Qualitymark, 1996.

NAVARRO, R. F. A evolução dos materiais. Parte 1: da préhistória ao Início da Era Moderna. REMAP, Campina Grande/PB, V1, p. 4,01112006. Disponível: http://aplicweb.feevale.br/site/files/docume ntos/pdf/32246.pdf. Acessado em 27 mar. 2014.

PORTER, M.; LINDE, C. V. D. Green and competitive: ending the stalemate. HBR - 
Harvard Business Review, p. 120-134, set. /out. 1995.

SILVA, C. L. (org). Desenvolvimento Sustentável: um conceito multidisciplinar. Petrópolis: Vozes, 2005.

SAVITZ, A. W. The triple bottom line: how today's best-run companies are achieving economic, social, and environmental success-and how you can too. San Francisco: Jossey-Bass, 2006. Disponível em <http://cs5141.userapi.com/u133638729/do cs/5ccd55378e88/Andrew_W_Savitz_The_Tri ple_Bottom_Line_How_Toda.pdf>. Acesso em 02 dez. 2012. 